\title{
EDITORIAL
}

\section{Impact of the COVID-19 pandemic on pharmacy education in Kuwait}

\author{
Pierre Moreau \\ Faculty of Pharmacy, Kuwait University, Kuwait
}

\author{
Correspondence \\ Pierre Moreau \\ Faculty of Pharmacy \\ Health Sciences Centre \\ Kuwait University \\ Jabriya Block 4 \\ Kuwait \\ Pmoreau@hsc.edu.kw
}

\begin{abstract}
Amidst a challenging pandemic, Kuwait has opted to close public schools and Kuwait University for nearly six months. Education has resumed with online modalities for learning and assessment, after a period of training for both instructors and students. The impact of this conservative approach on academic life, workforce provision and the evolution of the profession are discussed. Social aspects of the pandemic are also explored.
\end{abstract}

Kuwait is a Middle Eastern country of approximately 4.3 million people, $28 \%$ of whom are Kuwaiti citizens and the remainder of which are expatriate workers. As of 20th November 2020, Kuwait authorities have reported 140,000 cases and 863 deaths (0.6\% of cases and 200 deaths per million population) due to COVID-19 (Ministry of Health Kuwait, 2020). When the outbreak started in Iran, a neighbouring country, several measures were rapidly taken to curb the spread of the virus in Kuwait. Amongst those measures, the Ministry of Education closed all schools and universities as of 1st March 2020. In the public sector - of which Kuwait University is part, hosting the only college of pharmacy of the country education in all forms was suspended until 9th August 2020. Meanwhile, private institutions were allowed to continue with remote education modalities (Al-Taweel et al., 2020). The minister has been criticised by the national assembly for being hesitant to establish a clear policy, but the author knows that there was no easy solution to protect the population against the effects of the pandemic. On 9th August 2020, university education resumed the second semester of the 2019-2020 academic year, using distant education and assessment methods. As of yet, there is no announcement regarding resuming on-campus education at some point. However, the university conducted the final examinations of the 2019-2020 academic year on-site in October. This was done while respecting the guidelines of the ministry of health to limit the spread of the disease by wearing masks, washing hands, and complying with physical distancing.

The long pause from March to August has created a peculiar situation during which the educators were waiting for new directives as the situation evolved, while the students were slowly losing their motivation to keep academically active. This even led to some form of social isolation that affected some students (Al-Taweel et al., 2020). The long break, without face-to-face meetings and limited expectations from the institution, became a challenge for keeping the momentum going on special projects. For instance, our faculty had planned workshops on active learning strategies for March to support the implementation of our new Pharm.D. curriculum for the autumn of this year. Those support activities were postponed until more normal activities can resume, but we are currently considering moving them to online modalities as well. 
The positive aspect of the long pause is that educators and students were given enough time to train on the main online platforms to prepare for the August reboot. With travelling prohibited during the usual summer vacations, June and July were used quite effectively to train all the personnel and the students on the use of Microsoft Teams and Moodle as the main platforms to conduct synchronous and asynchronous learning activities, respectively. Our faculty already used Moodle quite extensively in the past to support educational activities, and only certain functions, like the assessment modalities, had to be learned. Most time and energy went into learning how to use Microsoft Teams in the context of live class interactions. Holding departmental and faculty meetings online helped to get a hold of the new tools. Moving towards online education modalities was facilitated by the fact that more than $95 \%$ of our students are Kuwaiti and are generally appropriately equipped in terms of electronic devices and Wi-Fi access in their home.

We were also able to learn from other universities that went ahead with online education in the spring and summer. This was especially true for more specialised courses like laboratories and clinical placements, that require more innovative solutions. The FIP webinars that were given on these topics throughout the summer were very helpful for learning from the experience of others. In general, the continuation of the academic year in August was quite successful, but as K-12 schooling activities are now restarting online, students and academic staff who are parents of young children are struggling to focus on their own duties. Of course, the impact of homeschooling is not limited to the educational sector, but we have a significant number of our students that have young children. Indeed, Kuwaiti, as a society, generally marry and start having their family in their early twenties. Students revealed that they do not have a quiet area in their house to follow online classes or assessment and are regularly disturbed by their bored children. With homeschooling, the situation is just getting worse, as parents have to tend for their children's learning environment and activities.

In terms of impact on the workforce, the graduation of the 2020-class was delayed by several months until the end of October instead of June. In addition to our graduates, the Ministry of Health has been actively recruiting pharmacists from abroad, a process that was also stalled. The limited travelling possibilities contributed to the negative impact on workforce mobility, both at the level of the pharmacists and academic staff. For example, staff that were recruited late last year or earlier this year are still waiting to join us. So, although the healthcare system was (and still is) under a lot of pressure, the workforce renewal and expansion were very limited. It is not clear if there will be a long-term impact of the pandemic on the pharmacy and university workforce capacity. It will most likely depend on the duration of the travelling restrictions imposed by the pandemic and the capacity of people to move freely between countries. Kuwait currently has a travel ban with 31 countries, some of which are a usual source of expatriate workers in the pharmacy sector.

As with the general population, about $25 \%$ of pharmacists are Kuwaiti, and they mostly work within the Ministry of Health polyclinic and hospital network. The university's recent provision of Pharm.D. graduates (from a two-year add-on Pharm.D. programme), in addition to pharmacists coming to the country with a more clinical education, is helping to reshape the role of the pharmacist towards an expanded scope of practice. We do not think that the pandemic has slowed down the progression of the profession's evolution. To the contrary, it may have actually improved the inter-professional collaboration during these trying times, thus opening up new possibilities for the near future.

\section{References}

Al-Taweel, D., Al-Haqan, A., Bajis, D., Al-Bader, J., Al-Taweel, A. M., Al-Awadhi, A., \& Al-Awadhi, F. (2020). Multidisciplinary academic perspectives during the COVID-19 pandemic. The International Journal of Health Planning and Management, 35, 1295-1301. https://doi.org/10.1002/hpm.3032

Ministry of Health Kuwait. (2020). COVID-19 Updates (online). Available at: https://corona.e.gov.kw/en 